\title{
Obligatoriedad en la salud o fascismo sanitario
}

\author{
José Luis Sandoval-Gutiérrez
}

Servicio de Neumología, Instituto Nacional de Enfermedades Respiratorias Ismael Cosío Villegas, Ciudad de México, México

El Dr. Lifshitz ${ }^{1}$ presenta un editorial interesante sobre la campaña de una región de Italia que pretendía que la salud debía ser obligatoria y que quien no la obedeciera tendría pena de muerte. Esta pretensión, que de entrada resulta simpática, quizá muestra la desesperación de un sistema de salud que se ve rebasado presupuestalmente con el incremento de la esperanza de vida y, por ende, de la presentación de enfermedades crónicas degenerativas en la población.

Desde hace décadas, la formación médica hace hincapié en la importancia de la prevención como la medida más eficaz en la preservación de la salud en una comunidad, pero paradójicamente es la forma curativa la que más se enseña en las escuelas y se estudia en las especialidades.

Los médicos estamos convencidos de que la salud es el tesoro más grande del ser humano, y así nos lo hacen saber los pacientes cuando están enfermos y desean la pronta recuperación de su mal. Cuando este pasa nos preguntamos: ¿por qué no viene a sus consultas?, ¿por qué no se toma los medicamentos?, ¿por qué no sigue las medidas sugeridas? Y quizás la respuesta mediata será porque así es el género humano.

Generalmente, ningún individuo desea estar enfermo ni siquiera en el pensamiento; el negar la realidad o la posibilidad de sufrir algún padecimiento hace que se evadan las condiciones para tener un estado saludable. Hay un estado de pensamiento de búsqueda de bienestar que se confunde con la satisfacción o el placer que pueden dar algunas situaciones: fumar, beber, sedentarismo, situaciones extremas en el transporte, sexo sin protección, toxicomanías, etc.

Nuestros antepasados presumían la no visita con los médicos como una situación de buena salud. Actualmente la gente está más informada, pero como bien se comenta en el editorial no necesariamente más educada; ahora se presume acudir con cierta periodicidad con el médico, pero la visita a este no es sinónimo de acatar las recomendaciones que haga.

El libre albedrío, tradicionalmente considerado un valor desde el punto de vista religioso, humanístico y legal, trasciende por desgracia al campo de la salud y el paciente considera que él está en su derecho de acudir al sistema de salud cuando así lo considere necesario y de seguir las indicaciones cuando lo crea conveniente. Las anteriores situaciones serían la máxima expresión de la libertad en una sociedad moderna, pero desde el punto de vista sanitario son una tragedia.

Hay varios ejemplos a través de la historia médica de que el Estado obliga a su población a tomar ciertas medidas sanitarias de carácter obligatorio (Cuba, antigua URSS, etc.), pero siempre será preferible y deseable desde el punto de vista ético y bioético la sana responsabilidad individual en su salud, sin la necesidad de penalización para la misma.

\section{Bibliografía}

1. Lifshitz A. Health is obligatory. Gac Med Mex. 2016;152:149-50.

\section{Correspondencia:}

José Luis Sandoval-Gutiérrez

Servicio de Neumología, Instituto Nacional de Enfermedades Respiratorias Ismael Cosío Villegas Ciudad de México, México

E-mail: sandovalgutierrez@gmail.com
Fecha de recepción: 11-02-2017

Fecha de aceptación: 01-06-2017

DOI:10.24875/GMM.17003295
Gac Med Mex. 2017;153:695

Contents available at PubMed www.gacetamedicademexico.com 